\title{
Evolução das características da planta associadas à nutrição nitrogenada de repolho
}

\author{
Marialva Alvarenga Moreira ${ }^{1}$, Sanzio Mollica Vidigal ${ }^{2}$
}

\section{RESUMO}

A execução adequada do programa de adubação na cultura do repolho pode ser obtida pela sincronização da demanda da planta com o suprimento de $\mathrm{N}$ durante o ciclo da cultura. Assim, o objetivo deste trabalho foi avaliar a evolução de indicadores nutricionais, a intensidade da cor verde (índice SPAD), medida na quarta folha completamente expandida; o teor de nitrogênio total e o teor de nitrato e as características agronômicas, comprimento do caule, número de folhas e massas de matéria fresca e seca de folhas, caules e raízes da planta, para determinar o teor de nitrogênio no repolho e determinar o valor crítico de cada característica em diferentes épocas de avaliação. Aos 50, 64 e 78 dias após a semeadura, foram determinados: a intensidade da cor verde (índice SPAD), medida na quarta folha; o comprimento do caule, o número de folhas, as massas de matéria fresca e seca e o teor de $\mathrm{N}$ foliar. Foram avaliadas cinco doses de $\mathrm{N}$ ( 0 ; $75 ; 150 ; 300$ e $450 \mathrm{~kg} \mathrm{ha}^{-1}$ ). Os tratamentos foram arranjados no delineamento experimental de blocos ao acaso, com quatro repetições. A colheita final das cabeças de repolho ocorreu aos 103 dias após a semeadura. Os valores ótimos das variáveis ao longo do tempo dependeram das doses de $\mathrm{N}$ e da época de avaliação. O valor ótimo do índice SPAD foi de 60,8; 58,4 e 53,5 aos 50; 64 e 78 dias após a semeadura. O valor ótimo do teor de nitrogênio total foi de 62,9; 60,3 e 59,0 $\mathrm{g} \mathrm{kg}^{-1}$ nas folhas, de 48,6; 40,6 e 40,3 $\mathrm{g} \mathrm{kg}^{-1}$ no caule e de 39,9; 36,9 e 20,1 $\mathrm{g} \mathrm{kg}^{-1}$.nas raízes aos 50,64 e 78 dias após a semeadura.

Palavras-chave: Brassica oleracea L., diagnóstico nutricional, nível crítico.

\section{ABSTRACT}

\section{Plant parameters associated with adequate nutritional nitrogen status of cabbage}

Correct management of cabbage fertilization can be achieved by synchronizing the plant demand with $\mathrm{N}$ supply during the crop cycle. The objective of this study was to evaluate the evolution of nutritional parameters intensity of green color (SPAD index) taken on the fourth fully expanded leaf, $\mathrm{N}$ content, stem length, number of leaves, and fresh and dry matter weights to diagnose nitrogen status of cabbage and determine the critical value of each parameter at different assessment times. At 50, 64 and 78 days after sowing, the intensity of green color (SPAD index) measured on the fourth leaf, stem length, number of leaves, fresh and dry matter weights and $\mathrm{N}$ content in the leaf dry matter were determined. Five $\mathrm{N}$ rates $\left(0,75,150,300\right.$ and $\left.450 \mathrm{~kg} \mathrm{ha}^{-1}\right)$ were evaluated. Treatments were arranged in a randomized block design with four replications. Last harvest of cabbage heads was at 103 days after sowing. Optimal values of variables over cabbage cycle depended on $\mathrm{N}$ rates and time of evaluation. Optimal SPAD values were 60.8, 58.4 and 53.5 at 50, 64 and 78 days after sowing respectively. Optimal values of $\mathrm{N}$ content were 62.9, 60.3 and 59.0 in the leaves, $48.6,40.6$ and 40.3 in the stem and 39.9, 36.9 and 20.1 in the roots.

Key words: Brassica oleracea L., nutritional diagnosis, critical level.

Recebido para publicação em janeiro de 2010 e aprovado em fevereiro de 2011

${ }^{1}$ Engenheira Agrônoma, Doutora, Pós doutoranda, bolsista FAPEMIG, EPAMIG Zona da Mata, Empresa de Pesquisa Agropecuária de Minas Gerais, Vila Gianetti, Casa 46, Campus da UFV, 36571-000 - Viçosa, MG, Brasil. marialvamoreira@yahoo.com.br

${ }^{2}$ Engenheiro Agrônomo, Doutor, Pesquisador, Bolsista BIPDT/FAPEMIG, EPAMIG Zona da Mata, Empresa de Pesquisa Agropecuária de Minas Gerais, Vila Gianetti, Casa 46, Campus da UFV, 36571-000 - Viçosa, MG, Brasil. sanziomv@epamig.ufv.br. 


\section{INTRODUÇÃO}

O repolho (Brassica oleracea var. capitata) é hortaliça herbácea, com folhas arredondadas e cerosas, formando uma cabeça compacta. Ao longo do tempo, foram obtidos cultivares adaptados a temperaturas elevadas, ampliando-se, consequentemente, os períodos de plantio e de colheita. Assim, pela escolha criteriosa do cultivar, a época de plantio estende-se ao longo do ano, em diversas regiões produtoras (Filgueira, 2000). Para obter alta produtividade e máximo retorno econômico, necessita-se de adubação. Dentre os nutrientes limitantes, o nitrogênio (N) merece destaque. Quase sempre é necessário aplicar fertilizante nitrogenado, em dose adequada, para a obtenção de plantas com cabeça de repolho com a compacidade (firmeza) desejada pela aceitação comercial.

No campo, a fertilização com $\mathrm{N}$ aumenta a produção (Huang et al., 2004; Aquino et al., 2005a; Din et al., 2007) e otimiza a qualidade de repolho (Aquino et al., 2005b; Haque et al., 2006). Escassez de $\mathrm{N}$ pode resultar em baixa produtividade e cabeças menores, por causa da reduzida área foliar (Cardoso \& Hiraki, 2001; Torres et al., 2003). Por outro lado, excesso de $\mathrm{N}$ favorece o crescimento excessivo das folhas, reduz os teores de açúcares e de vitamina $\mathrm{C}$ e a massa da matéria seca da cabeça (Kano et al., 2007; Din et al., 2007).

Portanto, é necessário executar corretamente o programa de adubação na cultura. Melhoria na eficiência de aplicação do $\mathrm{N}$ pode ser conseguida pela sincronização da demanda da planta com o suprimento de $\mathrm{N}$ durante o ciclo da cultura. A oferta de $\mathrm{N}$ deve ser sincronizada com o requerimento do nutriente, em tempo real, por meio de aplicações periódicas, o que se pode alcançar parcelando a adubação nitrogenada, definida pela avaliação do estado nutricional da planta.

Usualmente, a avaliação do estado de $\mathrm{N}$ é acoplada à resposta da planta à fertilização via solo e pode ser feita por meios diretos e indiretos, com uso de índices apropriadamente calibrados (Olfs et al., 2005; Fontes \& Araújo, 2007). Mais comumente, o critério para monitorar os teores de $\mathrm{N}$ e de $\mathrm{N}-\mathrm{NO}_{3}$ da planta é a análise química da matéria seca da folha, em laboratório. Usa-se geralmente a quarta folha completamente desenvolvida (Fontes \& Araújo, 2007). Tais análises são onerosas, demoradas e realizadas por pessoas qualificadas.

Atualmente, em consonância com a agricultura de precisão, índices ou testes para avaliar o estado de $\mathrm{N}$ precisam ser rápidos, práticos e eficazes (Fontes, 2001). Assim, estudos têm sido publicados, utilizando-se a análise da intensidade da cor verde da planta. $\mathrm{O}$ teor de clorofila ou o verde da folha tem sido indicado como índice para avaliar o estado de N. Isso devido ao fato de doses diferentes de $\mathrm{N}$ proporcionarem diferentes tons de verde na folha.

Assim, a cor verde da folha, representada pelo teor de clorofila, que pode ser medida por medidor portátil SPAD-
502, de forma instantânea e de maneira não destrutiva, surgiu como alternativa para avaliar o teor de $\mathrm{N}$ (Westerveld $e t$ al., 2003; Westerveld et al., 2004; Fontes \& Araújo, 2007). Várias pesquisas têm demonstrado que o teor de clorofila medido com o SPAD-502 correlaciona-se com a concentração de nitrogênio na planta e, também, com o rendimento de diversas espécies, inclusive repolho (Westerveld et al., 2003; Westerveld et al., 2004), podendo ser usado como ferramenta auxiliar na decisão sobre adubação nitrogenada da cultura no campo. Tais testes são rápidos, podem ser feitos no campo e permitem o sensoriamento, em tempo real, do estado nutricional de nitrogênio da planta (Fontes \& Araújo, 2007) e podem-se tornar uma alternativa viável para o sistema de produção de repolho.

Adicionalmente, características morfológicas da planta, determinadas com facilidade e de forma não destrutiva, como área da folha, número de folhas e altura de plantas, talvez possam ser utilizadas como teste indireto para avaliar o estado de $\mathrm{N}$, em alternativa ou em complementaridade à análise do verde da folha (Fontes, 2001).

Qualquer que seja o teste, é necessário interpretar os valores obtidos. Para isso, é preciso haver a disponibilidade do valor considerado referencial, ou ótimo, para cada teste, em determinados estádios fisiológicos da planta. A literatura não contempla informações com tal direcionamento na cultura do repolho. Existem alguns trabalhos, em condições de campo, que procuram estabelecer índices para avaliar o teor de nitrogênio de repolho (Huett \& Rose, 1989; Westerveld et al., 2003; Westerveld et al., 2004). Entretanto, tais informações não incluem aspectos da evolução dos índices para avaliar o teor de $\mathrm{N}$, ao longo do tempo, no sistema de produção de repolho.

Assim, o objetivo deste trabalho foi avaliar a evolução dos indicadores nutricionais, intensidade da cor verde da folha, medida na quarta folha completamente expandida, teor de nitrogênio total e teor de nitrato e as características agronômicas, comprimento do caule, número de folhas e massas da matéria fresca e seca de folhas, caules e raízes da planta, para determinar o estado de nitrogênio de repolho e determinar o valor crítico de cada indicador, em diferentes épocas de avaliação.

\section{MATERIAL E MÉTODOS}

O experimento foi conduzido na fazenda experimental da EPAMIG, Oratórios, Minas Gerais, no período de 02/ $07 / 08$ a 13/10/08. Foram avaliadas cinco doses de $\mathrm{N}(0 ; 75$; $150 ; 300$ e $450 \mathrm{~kg} \mathrm{ha}^{-1}$ ), sendo cada dose aplicada em cobertura, em três parcelas iguais, aos 43, 57 e 71 dias após a semeadura. A fonte de $\mathrm{N}$ foi uréia. Os tratamentos foram arranjados no delineamento experimental de blocos ao acaso, com quatro repetições. A semeadura ocorreu em 02/07/08, em bandejas de poliestireno expandido, com 128 células, preenchidas com substrato comercial Plantmax ${ }^{\circledR}$. O transplantio das mudas ocorreu em $04 / 08 / 08$, tendo elas 
de 3 a 4 folhas completas, utilizando-se o espaçamento de 0,40 x 0,50 m. A parcela foi constituída de oito linhas, com 15 plantas cada, e a parcela útil constou de 44 plantas das quatro linhas centrais.

O solo, Argissolo Vermelho-Amarelo, da área de cultivo, apresentava, na camada de $0-20 \mathrm{~cm}$ de profundidade, as seguintes características: $\mathrm{Ca}=1,0 ; \mathrm{Mg}=0,3 ; \mathrm{Al}=0,5$; $\mathrm{H}+\mathrm{Al}=3,96$, expressos em $\mathrm{cmol}_{\mathrm{c}} \mathrm{dm}^{-3} ; \mathrm{P}=21,8 \mathrm{mg} \mathrm{dm}^{-3}$ (Mehlich 1); $\mathrm{K}=43,0 \mathrm{mg} \mathrm{dm}{ }^{-3}$; matéria orgânica = 11,0 g $\mathrm{kg}^{-1}$ e $\mathrm{pH}$ (água) $=4,5$.

O preparo do solo constou de aração, gradagem e abertura dos sulcos com $15 \mathrm{~cm}$ de profundidade. A adubação de plantio, com base na análise de solo e nas recomendações de Ribeiro et al., 1999, consistiu em $1.500 \mathrm{~kg} \mathrm{ha}^{-1}$ de superfosfato simples, $80 \mathrm{~kg} \mathrm{ha}^{-1}$ de cloreto de potássio, 20 $\mathrm{kg} \mathrm{ha}^{-1}$ de bórax e $20 \mathrm{~kg} \mathrm{ha}^{-1}$ de sulfato de zinco. Utilizaram-se também $100 \mathrm{~kg} \mathrm{ha}^{-1}$ de cloreto de potássio, aplicado em duas parcelas, juntamente com a primeira e segunda aplicações do adubo nitrogenado, em cobertura. As mudas foram transplantadas no espaçamento de $0,40 \mathrm{x}$ $0,50 \mathrm{~m}$. Os tratos culturais, controle de pragas e irrigação por aspersão convencional, foram aplicados de acordo com as necessidades, conforme as recomendações para a cultura (Vidigal et al., 2007).

As avaliações foram feitas aos sete dias após a aplicação de $\mathrm{N}$ em cada tratamento. Assim, foram realizadas três avaliações, aos 50, 64 e 78 dias após a semeadura. As determinações feitas foram: intensidade da cor verde da folha, medida na quarta folha completamente expandida, comprimento do caule, número de folhas e massas da matéria fresca e seca de folhas, caules e raízes da planta. A intensidade do verde da folha foi determinada no folíolo terminal da QF, entre 8 e 11 horas, com o medidor portátil de clorofila denominado SPAD-502 (Soil Plant Analysis Development-502).

Posteriormente à determinação das massas da matéria fresca de folhas, caules e raízes, as amostras foram acondicionadas em sacos de papel e colocadas em estufa de circulação forçada de ar, a $70{ }^{\circ} \mathrm{C}$, até massa constante, quando foi determinada a massa da matéria seca. Após a secagem, o material seco foi moído em moinho tipo Wiley, equipado com peneira de 20 mesh, submetido à digestão sulfúrica, para a determinação dos teores de $\mathrm{N}$ total por titulometria, após destilação em microdestilador de Kjeldahl. Em outra subamostra, o N-NO foi extraído com água desmineralizada em banho-maria, a $45^{\circ} \mathrm{C}$ por $1 \mathrm{~h}$, determinando-se a concentração de $\mathrm{N}-\mathrm{NO}_{3}$ por colorimetria, em espectrofotômetro a 410nm (Cataldo et al., 1975).

A colheita ocorreu quando as cabeças alcançaram a compacidade (firmeza) desejada pela aceitação comercial, sendo colhidas e pesadas. Os dados foram submetidos às análises de variância e de regressão, utilizando-se o programa SAEG (FUNARBE, 1993) a 10\% de probabilidade, ajustando-se o modelo que melhor descrevesse a relação entre as variáveis dependente e independente. O nível crí- tico (NC) foi estimado associando-se os valores de cada característica, em cada época de avaliação, com a dose de $\mathrm{N}$ total que propiciou a massa de matéria fresca máxima de cabeça (Fontes, 2001). Assim, para cada época, o valor do nível crítico de cada índice selecionado foi estimado, com a dose de $\mathrm{N}$ total associada à massa de matéria fresca máxima de cabeça, na colheita final, introduzida no modelo previamente estabelecido. Esse valor foi de $277,8 \mathrm{~kg} \mathrm{ha}^{-1}$ para a produção de massa de matéria fresca de cabeça de $1142 \mathrm{~g}$ planta $^{-1}$.

\section{RESULTADOS E DISCUSSÃO}

$O$ índice SPAD na quarta folha $(\mathrm{QF})$ respondeu de forma diferenciada ao incremento de doses de $\mathrm{N}$ e à época de avaliação (Figura 1). Aos 50 dias após a semeadura (DAS), não houve resposta do índice SPAD ao incremento da adubação nitrogenada, obtendo-se o valor médio de 60,8. Aos 64 e 78 DAS houve aumento quadrático em função da adubação nitrogenada, atingindo-se os valores máximos de índice SPAD de 59 e 53, respectivamente. Aumento do índice SPAD na QF, com o incremento de doses de N, foi obtido por Westerveld et al. (2003) e Westerveld et al. (2004) em repolho. Correlação positiva, entre a adição de nitrogênio e o verde da planta, ou teor de clorofila na folha de repolho, foi obtida por Westerveld et al. (2004).

$\mathrm{O}$ valor do índice SPAD na QF decresceu ao longo do ciclo da cultura, obtendo-se, assim, os valores de 60,8; 58,4 e 53,5 aos 50; 64 e 78 DAS (Tabela 1). O valor crítico estimado do índice SPAD ao longo do ciclo está abaixo do encontrado, 70,6, por Westerveld et al. (2004), que foi determinado no estádio de início do aparecimento das cabeças do cultivar Atlantis. Os valores de níveis críticos com o medidor portátil SPAD-502 são variáveis, precisando ser ajustados para cada situação, como deficiência de nutrientes e condições ambientais (Spaner et al., 2005), variedade (Hoel, 2003) e estádio de crescimento da cultura (Ramesh et al., 2002).

$\mathrm{O}$ teor de $\mathrm{N}$ respondeu ao incremento de doses de $\mathrm{Ne}$ época de avaliação (Figura 1). Aumentos dos teores de N com o incremento da dose de N, também, foram encontrados por Huett \& Dettmann (1989) e Ekbladh et al. (2007). $\mathrm{O}$ valor crítico do teor de $\mathrm{N}$ aumentou ao longo do ciclo da cultura (Tabela 1). De acordo com Jones Júnior et al. (1991), a faixa adequada para teores de $\mathrm{N}$ foliar seria de 36 a $50 \mathrm{~g} \mathrm{~kg}^{-1}$. Os resultados obtidos no ensaio, para a variável em referência estão acima dessa faixa. O valor indicado por Min \& Lee (2006) é de 15 a $52 \mathrm{~g} \mathrm{~kg}^{-1}$ de $\mathrm{N}$ na folha de couve chinesa.

A exemplo dos dados obtidos para avaliação de $\mathrm{N}$, os teores de $\mathrm{N}-\mathrm{NO}_{3}$ responderam à adubação nitrogenada. A Figura 1 indica o modelo para cada relação. Também Aquino et al. (2005b) obtiveram aumentos do teor de $\mathrm{N}-\mathrm{NO}_{3}$ com o incremento da dose de $\mathrm{N}$ em repolho. $\mathrm{O}$ valor crítico do teor de $\mathrm{N}-\mathrm{NO}_{3}$ não apresentou consistência ao longo do ciclo 
da cultura (Tabela 1). Dentre outros fatores, a época do ano, o cultivar, a data de determinação e o ambiente podem ter influenciado o valor do nível crítico $\mathrm{N}-\mathrm{NO}_{3}$.

Na caracterização do crescimento do repolho, o comprimento do caule (CC) e o número de folhas (NF) responderam ao incremento de doses de $\mathrm{N}$ e época de avaliação (Tabela 2).

O CC e o NF aumentaram ao longo do ciclo da cultura e o valor crítico de cada relação está apresentado na Tabela 3. Aumentos de CC e NF, com o incremento na dose
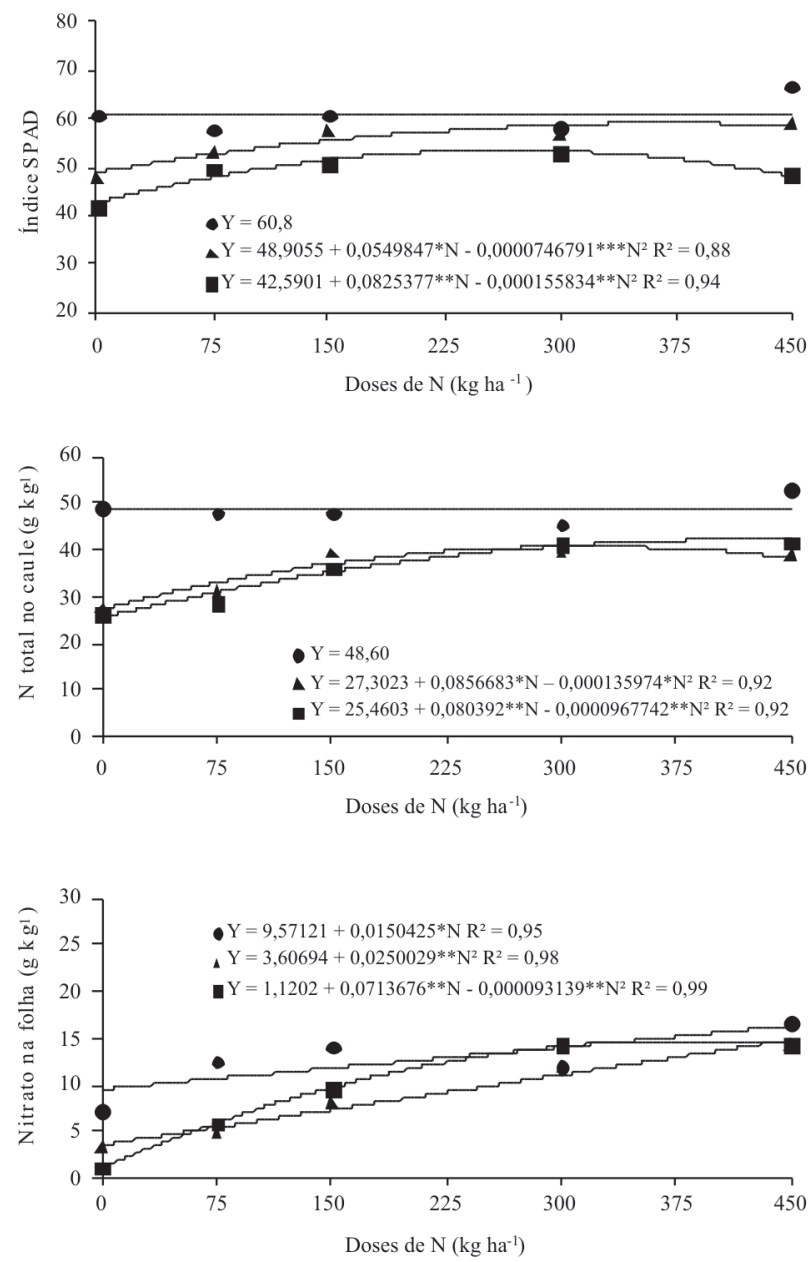

de $\mathrm{N}$ (Tabela 2), devem-se ao efeito promotor do $\mathrm{N}$ no crescimento (Cardoso \& Hiraki, 2001; Ferreira et al., 2002). Ekbladh et al. (2007) encontraram relação de proporcionalidade entre área foliar e nitrogênio, mostrando relação direta entre expansão da área foliar e absorção de N.

As características massas da matéria fresca e seca de folhas, caules e raízes responderam ao incremento de doses de $\mathrm{N}$ e à época de avaliação (incluídos na Tabela 2), aumentando ao longo do ciclo da cultura. O valor crítico de cada relação está inserido na Tabela 3.
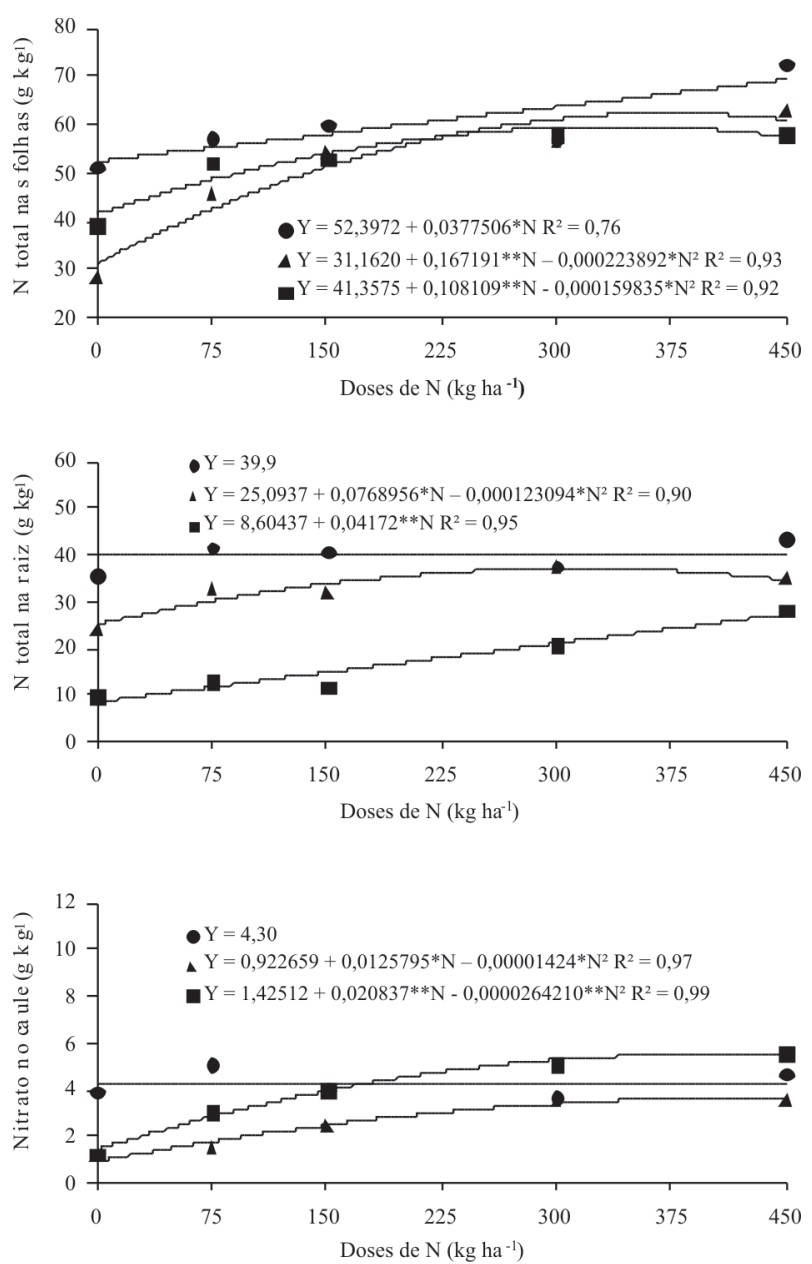

Figura 1. Índice SPAD na quarta folha, teor de nitrogênio total na folha, caule e raiz, e teor de nitrato na folha e caule em plantas de repolho, avaliadas aos $50(\bullet), 64(\bullet)$ e 78 (•) dias após semeadura, em função de doses de nitrogênio (N).

Tabela 1. Valores ótimos ${ }^{1}$ das características índice SPAD na quarta folha, teor de nitrogênio total e teor de nitrato em plantas de repolho, avaliadas aos 50, 64 e 78 dias após semeadura

\begin{tabular}{lccc}
\hline \multirow{2}{*}{ Características } & \multicolumn{3}{c}{ Ciclo da cultura (Dias após a semeadura) } \\
\cline { 2 - 4 } & $\mathbf{5 0}$ & $\mathbf{6 4}$ & $\mathbf{7 8}$ \\
\hline $\mathrm{SQF}$ (SPAD Quarta Folha) & 60,8 & 58,4 & 53,5 \\
$\mathrm{NF}$ (nitrogênio total folha $-\mathrm{g} \mathrm{kg}^{-1}$ ) & 62,9 & 60,3 & 59,0 \\
$\mathrm{NC}\left(\right.$ nitrogênio total caule $-\mathrm{g} \mathrm{kg}^{-1}$ ) & 48,6 & 40,6 & 40,3 \\
$\mathrm{NR}$ (nitrogênio total raiz $\left.-\mathrm{g} \mathrm{kg}^{-1}\right)$ & 39,9 & 36,9 & 20,1 \\
$\mathrm{NO}$ & 13 (nitrato folha $-\mathrm{g} \mathrm{kg}^{-1}$ ) & 10,5 & 13,7 \\
$\mathrm{NO}_{3} \mathrm{C}$ (nitrato caule $-\mathrm{g} \mathrm{kg}^{-1}$ ) & 4,3 & 3,3 & 5,2
\end{tabular}

${ }^{1}$ Quando houve efeito de dose, o valor foi estimado com a dose ótima de $\mathrm{N}$; quando não houve efeito de dose de $\mathrm{N}$, utilizou-se a média da variável.

Rev. Ceres, Viçosa, v. 58, n.2, p. 243-248, mar/abr, 2011 
Tabela 2. Comprimento do caule (CC), número de folhas (NF), massas de matéria fresca de folhas (MFF), caules (MFC) e raízes (MFR) e massas de matéria seca de folhas (MSF), caules (MSC) e raízes (MSR), da planta de repolho avaliadas aos 50, 64 e 78 dias após semeadura, em função de doses de nitrogênio $(\mathrm{N})$ e os respectivos coeficientes de determinação

\begin{tabular}{llc}
\hline Características & Equações ajustadas & $\mathbf{R}^{2} / \mathbf{r}^{2}$ \\
\hline \hline CC50 & $\hat{\mathrm{Y}}=3,24$ & - \\
CC64 & $\hat{\mathrm{Y}}=4,6722+0,00390113 * * * \mathrm{~N}-0,00000801826 * * * \mathrm{~N}^{2}$ & 0,74 \\
CC78 & $\hat{\mathrm{Y}}=7,29133+0,00298819 * * \mathrm{~N}$ & 0,79 \\
NF50 & $\hat{\mathrm{Y}}=8,34752-0,00184626 * \mathrm{~N}$ & 0,81 \\
NF64 & $\hat{\mathrm{Y}}=12,58$ & - \\
NF78 & $\hat{\mathrm{Y}}=17,1308+0,0164360 * \mathrm{~N}-0,0000271343 * * * \mathrm{~N}^{2}$ & 0,87 \\
MFF50 & $\hat{\mathrm{Y}}=22,24$ & - \\
MFF64 & $\hat{\mathrm{Y}}=344,488+1,85907 * \mathrm{~N}-0,00358684 * \mathrm{~N}^{2}$ & 0,89 \\
MFF78 & $\hat{\mathrm{Y}}=1502,73+9,02987 * * \mathrm{~N}-0,00996269 * * * \mathrm{~N}^{2}$ & 0,89 \\
MFC50 & $\hat{\mathrm{Y}}=1,68$ & - \\
MFC64 & $\hat{\mathrm{Y}}=19,2122+0,102577 * \mathrm{~N}-0,000180302 * * * \mathrm{~N}^{2}$ & 0,94 \\
MFC78 & $\hat{\mathrm{Y}}=117,429+0,920530 * \mathrm{~N}-0,00119190 * * * \mathrm{~N}^{2}$ & 0,78 \\
MFR50 & $\mathrm{Y}=0,70$ & \\
MFR64 & $\hat{\mathrm{Y}}=24,2396+0,0734564 * * * \mathrm{~N}-0,00014151 * * * \mathrm{~N}^{2}$ & 0,87 \\
MFR78 & $\hat{\mathrm{Y}}=218,26$ & - \\
MSF50 & $\hat{\mathrm{Y}}=2,22$ & - \\
MSF64 & $\hat{\mathrm{Y}}=39,0377+0,149188 * * * \mathrm{~N}-0,000283734 * * * \mathrm{~N}^{2}$ & \\
MSF78 & $\hat{\mathrm{Y}}=129,938+0,263283 * * \mathrm{~N}$ & 0,92 \\
MSC50 & $\hat{\mathrm{Y}}=0,25$ & 0,93 \\
MSC64 & $\hat{\mathrm{Y}}=0,551901+0,015254 * * * \mathrm{~N}-0,000033740 * * * \mathrm{~N}^{2}$ & - \\
MSC78 & $\hat{\mathrm{Y}}=11,8041+0,0231411 * * \mathrm{~N}$ & 0,83 \\
MSR50 & $\hat{\mathrm{Y}}=0,219052+0,000235632 * * * \mathrm{~N}$ & 0,86 \\
MSR64 & $\hat{\mathrm{Y}}=35,7578+0,149188 * * * \mathrm{~N}-0,000283734 * * * \mathrm{~N}^{2}$ & 0,62 \\
MSR78 & $\hat{\mathrm{Y}}=49,78$ & 0,92 \\
\hline
\end{tabular}

**, * e *** - significativos a 1,5 e $10 \%$ de probabilidade pelo teste "t", respectivamente.

Tabela 3. Valores ótimos ${ }^{1}$ das características agronômicas da planta de repolho, avaliadas aos 50, 64 e 78 dias após semeadura

\begin{tabular}{lccc}
\hline \multirow{2}{*}{ Características } & \multicolumn{3}{c}{ Ciclo da cultura (Dias após a semeadura) } \\
\cline { 2 - 4 } & $\mathbf{5 0}$ & $\mathbf{6 4}$ & $\mathbf{7 8}$ \\
\hline CC - (Comprimento do caule - cm) & 3,24 & 5,13 & 8,12 \\
NF- (No de folhas) & 7,83 & 12,58 & 19,60 \\
MFF (Massa fresca folha - g) & 22,24 & 584,13 & 3242,37 \\
MFC (Massa fresca caule - g) & 1,68 & 33,79 & 281,17 \\
MFR (Massa fresca raiz - g) & 0,70 & 33,72 & 218,26 \\
MSF (Massa seca folha - g) & 2,2 & 58,58 & 203,08 \\
MSC (Massa seca caule - g) & 0,25 & 2,27 & 18,23 \\
MSR (Massa seca raiz - g) & 0,28 & 55,30 & 49,76
\end{tabular}

${ }^{\mathrm{I}}$ Quando houve efeito de dose, o valor foi estimado com a dose ótima de N; quando não houve efeito de dose de N, utilizou-se a média da variável.

\section{CONCLUSÕES}

A variável índice SPAD, determinada na QF, e as características agronômicas da planta alcançaram valores críticos variáveis com a idade da planta de repolho.

O valor crítico do índice SPAD decresceu ao longo do ciclo de cultivo, atingindo o valor de 60,8; 58,4 e 53,5, aos 50; 64 e 78 dias após a semeadura.

$\mathrm{O}$ valor crítico do teor de nitrogênio total decresceu ao longo do ciclo de cultivo, atingindo os valores de 62,9; 60,3 e 59,0 $\mathrm{g} \mathrm{kg}^{-1}$, nas folhas, 48,6; 40,6 e 40,3 $\mathrm{g} \mathrm{kg}^{-1}$, no caule e 39,9; 36,9 e 20,1 $\mathrm{g} \mathrm{kg}^{-1}$ nas raízes, aos 50, 64 e 78 dias após a semeadura.

\section{AGRADECIMENTOS}

À FAPEMIG, pela bolsa de pós-doutorado do primeiro autor e pelo apoio financeiro.

\section{REFERENCIAS}

Aquino LA, Puiatti M, Pereira PRG, Pereira FHF, Castro, MRS \& Ladeira, IR (2005a) Características produtivas do repolho e função de espaçamento e doses de nitrogênio. Horticultura Brasileira, 23:266-270.

Rev. Ceres, Viçosa, v. 58, n.2, p. 243-248, mar/abr, 2011 
Aquino LA, Puiatti M, Pereira PRG, Pereira FHF, Ladeira IR \& Castro, MRS (2005b) Efeito de espaçamentos e doses de nitrogênio sobre as características qualitativas da produção do repolho. Horticultura Brasileira, 23:10-104.

Cardoso AII \& Hiraki, H (2001) Avaliação de doses e épocas de aplicação de nitrato de cálcio em cobertura na cultura do rabanete. Horticultura Brasileira, 9:328-331.

Cataldo DA, Harron M, Schrader LEL \& Youngs VL (1975) Rapid colorimetric determination of nitrate in plant tissue by nitration of salicylic acid. Communications in Soil Science and Plant Analysis, 6:71-80.

Din M, Qasim M \& Alam M (2007) Effect of different levels of $\mathrm{N}, \mathrm{P}$ and $\mathrm{K}$ on the growth and yield of cabbage. Journal of Agriculture Research, 45:171-176.

Ekbladh G, Witter E \& Ericsson, T (2007) Ontogenetic decline in the nitrogen concentration of field grown white cabbage Relation to growth components. Scientia Horticulturae, 112:149-155.

Ferreira WR, Ranal MA \& Filgueira FAR (2002) Fertilizantes e espaçamento entre plantas na produtividade da couve da malásia. Horticultura Brasileira, 20:635-640.

Filgueira FAR (2000) Novo Manual de Olericultura: agrotecnologia moderna na produção e comercialização de hortaliças. Viçosa, Editora da UFV, 402p.

Fontes PCR (2001) Diagnóstico do estado nutricional das plantas. Viçosa, Editora da UFV. 122p.

Fontes PCR \& Araujo C (2007) Adubação nitrogenada de hortaliças: princípios e práticas com o tomateiro. Viçosa, Editora da UFV, 148p.

FUNARBE - SAEG. Sistema para Análises Estatísticas (1993). v. 5.0. Viçosa.

Haque KMF, Jahangir AA, Haque ME, Ondal RK, Jahan MAA \& Sarker MAM (2006) Yield and nutritional quality of cabbages as affected by nitrogen and phosphorus fertilization. Journal Science Indian Research, 41:41-46.

Hoel BO (2003) Chlorophyll meter reading in winter wheat: cultivar differences and prediction of grain protein content. Soil Plant Science, 53:147-157.

Huang SW, Jin JY, Yang LP, Bai YL \& Li CH (2004) Spatial variability of nitrate in cabbage and nitrate-N in soil. Soil Science, 169:640-649

Huett DO \& Dettmann EB (1989) Effect of nitrogen on growth,quality and nutrient uptake of cabbages grown in sand culture. Australian Journal of Experimental Agriculture, 29: 875-881.
Huett DO \& Rose G (1989) Diagnostic nitrogen concentrations for cabbages grown in sand culture. Australian Journal of Experimental Agriculture, 29: 883-892.

Jones Júnior JB, Wolf B \& Mills HA (1991) Plant analysis handbook: a practical sampling, preparation, analysis and interpretation guide. Athens, Micro Macro Publishing. 213p.

Kano Y, Nakagawa H, Sekine M, Goto H \& Sugiura A (2007) Effect of nitrogen fertilizer on cell size and sugar accumulation in the leaves of cabbage (Brassica oleracea L. ). HortScience, 42:1490-1492.

Olfs HW, Blankenau K, Brentrup F, Jasper J, Link, A \& Lammel J (2005) Soil-and plant-based nitrogen-fertilizer recommendations in arable farming. Journal of Plant Nutrition and Soil Science, 168:414-431.

Min M \& Lee WS (2006) Nondestructive detection of nitrogen in Chinese cabbage leaves using vis-nir spectroscopy. HortScience, 441:162-166

Ramesh K, Chandrasekaran B, Balasubramanian TN, Bangarusamy U, Sivasamy R \& Sankaran N (2002) Chlorophyll dynamics in Rice (Oryza sativa) before and after flowering based on SPAD (Chlorophyll) meter monitoring and its relation with grain yield. Journal Agronomy Crop Science, 188:102-105.

Ribeiro AC, Guimarães PTG \& Alvarez VVH (1999) Recomendações para o uso de corretivos e fertilizantes em Minas Gerais. $5^{\text {a }}$ Aproximação. Comissão de Fertilidade do Solo do Estado de Minas Gerais. Viçosa, CFSEMG. 359p.

Spaner D, Todd AG, Navabi TA, Mckenzie DB \& Goonewardene LA (2005) Can leaf chlorophyll measures at differing growth stages be used as an indicator of winter wheat and spring barley nitrogen requirements in eastern Canada? Journal Agronomy and Crop Science, 191:393-399.

Torres JLR, Fabian AJ \& Pocay VG (2003) Níveis de adubação nitrogenada nas características morfológicas e produtivas do jiló. Horticultura Brasileira, 21:167-170.

Vidigal SM, Pereira PRG \& Pedrosa MW (2007) Repolho. In: Paula Júnior TJ \& Venzon M (Coords.) 101 Culturas: manual de tecnologias agrícolas. Belo Horizonte, EPAMIG. p. 655-674.

Westerveld SM, Mckeown AW, Mcdonald MR \& Scotto-Dupree CD (2003) Chlorophyll and nitrate meters as nitrogen monitoring tools for selected vegetables in southern Ontario. Acta Horticulturae, 627:25-266.

Westerveld SM, Mckeown AW \& Scotto-Dupree CD (2004) Assessment of chlorophyll and meters as field tissue nitrogen test for cabbage, onions and carrots. HortTechnology, 14:179188 . 